\title{
The Phenomenology of the Pipe Organ
}

Michael R. Kearney, Duquesne University, USA

Email: kearneym1@duq.edu

\begin{abstract}
An extended illustration from Merleau-Ponty's Phenomenology of Perception describes the interplay of habit, sedimentation, and intersubjectivity in the practice and performance of a skilled organist. This paper takes up Merleau-Ponty's example in order to describe some of the phenomenological characteristics of embodied musical performance. These characteristics point toward an intersubjective event of "consecration," as Merleau-Ponty describes it, in which the musician adopts the role of rhetor, inviting the audience into a shared dwelling place.
\end{abstract}

Keywords: gesture, habit, intersubjectivity, Maurice Merleau-Ponty, music, rhetoric

\section{Introduction}

In the midst of Maurice Merleau-Ponty's (1944/2012) investigation of habit in Phenomenology of Perception there appears the following striking excursus:

It is said that an experienced organist is capable of playing an organ with which he is unfamiliar and that has additional or fewer keyboards, and whose stops are differently arranged than the stops on his customary instrument. He needs but an hour of practice to be ready to execute his program. (p. 146)

Merleau-Ponty invokes the example of the pipe organ in order to support his claim that "habit resides neither in thought nor in the objective body, but rather in the body as the mediator of a world" (p. 146). A mechanistic or stimulus-response model assumes the centrality of the brain in establishing the dimensions and dynamics that constitute "objective space." In such a model, Merleau-Ponty contends, one would expect an organist to conduct a detailed analysis of the instrument and to form a mental "representation of the stops, pedals, and keyboards, as well as their relation in space" (p. 146). Actually, this "objective space" is nowhere to be found.

[D]uring the short rehearsal that precedes the concert, [the organist] hardly behaves like someone who wants to draw up a plan. He sits on the bench, engages the pedals, and pulls out the stops, he sizes up the instrument with his body, he incorporates its directions and dimensions, and he settles into the organ as one settles into a house. (p. 146)

Merleau-Ponty marvels at the playfulness and tactility that characterize the organist's encounter with a new instrument. The theoretical knowledge that the organist acquires from this session, if 
it can be called "theory" at all, emerges tacitly from the embodied activity of practice. Only gradually, as the rehearsal shifts into the concert, does "playing around on" the organ morph into playing the organ.

But when this transformation occurs, there is a seriousness and sobriety to the organist's actions. As practice yields to performance, it is the aesthetic demands of the music itself that guide the performer's interactions with the instrument:

During the rehearsal - just as during the performance - the stops, the pedals, and the keyboards are only presented to him as powers of such and such an emotional or musical value, and their position as those places through which this value appears in the world. Between the musical essence of the piece such as it is indicated in the score and the music that actually resonates around the organ, such a direct relationship is established that the body of the organist and the instrument are nothing other than the place of passage of this relation. From then on, the music exists for itself, and everything else exists through it. (Merleau-Ponty, 1944/2012, pp. 146-147)

Now Merleau-Ponty clinches his point: "the organist does not play within objective space" (p. 147). But it is the nature of the alternative he proposes, "expressive space," that captures the imagination of the reader. What, one wonders, does Merleau-Ponty intend by statements such as the following?

In fact, his rehearsal gestures are gestures of consecration: they put forth affective vectors, they discover emotional sources, and they create an expressive space, just as the gestures of the augur define the templum. (p. 147)

Notwithstanding the common associations between pipe organs and churches, Merleau-Ponty's religious metaphors come as a surprise. How does an organ rehearsal suggest consecration? What are the rites and rituals that transform this apparently ordinary interaction between a musician and his or her instrument into sacred time and sacred space? And what might Merleau-Ponty's elaboration of this musical example suggest for a study of human embodiment more generally?

Max van Manen's (2007) articulation of a phenomenology of practice directs attention to the places and times in which meaning springs forth in our embodied engagement with the world. The practice of playing a musical instrument offers a rich field of study for the tactility and aural awareness of a "pathic" mode of being in the world (p. 20). A phenomenology of practice approach commends closer examination of Merleau-Ponty's pipe organ example, not merely as a contrast between objective and expressive space, but also as an exploration of the relationship among habits, habitats, and consecration. What are the phenomenological implications of the claim that musical performance consecrates a particular place and time? Addressing such a question invites excursions into the philosophy of music, hermeneutic theory, and the rhetorical tradition. Although as an organist I can offer firsthand appreciation and confirmation of Merleau-Ponty's case study, the intent of this article is not to offer a phenomenological analysis from the organ bench, but rather to explore the sacralizing function of music from a phenomenological perspective. The themes of sacralization and dialogic engagement suggest a deeper significance to the intersubjective event of embodied musical performance than has been previously explored in Merleau-Ponty's work. 


\section{Prelude: The Corporeality of the Pipe Organ}

Before discussing Merleau-Ponty's specific example in detail, it is helpful to consider some of the distinctive characteristics of the pipe organ. Even the etymology of the word "organ" invokes the notions of mediation, communication, and embodiment. The Oxford English Dictionary (2019) reveals a remarkably wide horizon of significations. Historically, the word's French, Greek, and Latin roots connote not only a musical set of pipes and keys, but also "something that acts as an instrument or means," "agency," a "faculty," a "person who acts as an intermediary," or even a "means of communication or expression of opinion." The OED connects "organ" to the Greek "̌prov, suggesting the idea of "that with which one works." In its ancient usage, "organ" signified instrumentality in its broadest sense: the human faculty of creating and exploiting material objects as media of expression and communication. Even today, the word "organology" refers not specifically to the study of the pipe organ, but to the study of musical instruments generally.

In an out-of-the-way passage in his Expositions on the Psalms, Augustine of Hippo (1966) indicates that the Latin organum refers not only to an instrument "which is large and inflated by bellows" but also to any instrument that is corporeum, or bodily (p. 705). Augustine's insistence on the corporeality of the organ is obscure to modern readers; he might merely mean that organs are particularly suited to accompany the human voice, or he might be analogizing between musical organs and bodily organs. ${ }^{1}$ Some contemporary translators have found Augustine's excursus on the organ so archaic that they have edited it out (Augustine, 2001, p. 117). But there is another possible sense in which to take Augustine. To connect the organ with corporeality hints at the fuzzy interaction between the embodiment of flesh and blood and the artifice of instrumentality. As a "corporeal" instrument, the pipe organ resides in the liminal space between body and technology. If this phenomenological observation seems too subtle to ascribe to Augustine's purposes in his commentary, it at least foreshadows the analysis that Merleau-Ponty conducts in Phenomenology of Perception.

The terminology of pipe organ construction further bears out the metaphorical relationship between the organ and the human body: the organ's pipes are linked to "chests" holding air, which, when it passes over the upper and lower "lips," allows each pipe to "speak." Organ builders engage in a process of "voicing," which involves minute adjustments to the pipes in order to blend their volume and timbre. These metaphors emphasize that the pipe organ is a mechanical simulation of the human apparatus of speech. As a result, the craft of organ building and the art of organ performance both depend heavily upon the artist's attunement to the dynamics of the human voice, as Roger E. Davis (1985) makes clear in his Organists' Manual:

The human voice is the natural medium of musical expression. Vocal phrases are unified and supported, each by a single breath, and divisions of phrases are marked by the intake of breath.... In organ music there are breathing places just as there are in speech and song, and the musically sensitive organist can bring life and vitality to the music by imitating singers and wind players - by allowing the music to breathe. (p. 45)

\footnotetext{
${ }^{1}$ Of course, the organs to which Augustine refers would have looked and sounded considerably different than a modern pipe organ, but the underlying musical principles remain the same (Owen, Williams, \& Bicknell, 2001).
} 
From a musician's perspective, Davis describes what the foregoing etymological discussion reveals: the root metaphor of the pipe organ is the embodied act of speech and song itself.

But speech, of course, does not occur in a vacuum. And while the organist is privy to the exhilarating tactility of the keyboards and the vibrations of the pipes throughout the instrument, his or her sensory experience is incomplete unless consummated by the presence of an audience in the room who can enjoy the resulting art. Nowhere is this more clearly evident than when organist and congregation unite in corporate singing. Here the organ morphs from a specimen of human ingenuity into a medium of communication with the divine. John Walker, past president of the American Guild of Organists, recently stated that his true source of joy at the bench of the church organ came not from the sound of the pipes but from the sound of the congregation singing back at them (Williams \& Walker, 2018). At its best, the church organ serves as a support and encouragement to strong congregational singing - the ensemble of natural organs of praise, human voices, which it can only imperfectly imitate. At its worst, the pipe organ serves as an instrument of distraction and discord, obscuring rather than facilitating the sacred dialogue at the heart of worship (Kuyper, 1911/2009, pp. 56-57). Thus the early Dutch Reformed church synods, although situated in one of the world's most splendid periods of organ building, consistently objected to the use of organs in services, claiming that the music "mostly causes the people to forget what was previously heard" in the sermon (Provincial Synod of Dordrecht, 1982, p. 68). Whereas the organ at its finest withdraws from conscious perception into the dialogic fabric of worship, it may also become a reification of the human voice in wood and stone - the classic definition of an idol (Psalm 115).

One aspect is still missing from this discussion: the acoustic significance of the space in which a pipe organ resides. A maxim of organ builders and organists is that the most important set of pipes on the organ is the room in which it is placed (Associated Pipe Organ Builders of America, 2018). At a basic level, this involves an admission of the space needed to accommodate the organ's sheer size. The largest and loudest musical instruments in the world are pipe organs, with the instrument in the Boardwalk Hall Auditorium in Atlantic City, New Jersey, topping the list (Guinness World Records, 2020). Such mammoths require immense spatial and architectural resources simply in order to exist, and because of their staggering maintenance requirements they are rarely fully functional at any given time. But the incredible dynamic range of the pipe organ also depends in large part on the possibilities provided by the ambience of the surrounding space. Architectural nuances as subtle as the texture of the paint on the ceiling or the presence or absence of cushions on the pews open and limit the acoustic possibilities of the organ (Associated Pipe Organ Builders of America, 2018). Other instruments acquire their resonance through the construction of their own bodies, but the organ derives its resonance from the building itself. Any audience member who has experienced the vibrations set off by a particularly deep pedal note can attest that the pipe organ provides an enveloping and deeply corporeal experience, no less felt than heard. Thus, the pipe organ is a particularly fitting example of the kind of embodied knowledge that a phenomenological approach considers.

The foregoing discussion is intended to contextualize the remarks I will be making in the remainder of this paper by tying them to musical and historical foundations. In turning to secondary phenomenological literature that addresses Merleau-Ponty's pipe organ example, I will unavoidably return to some of the themes mentioned above. Now, however, I will do so by considering three key metaphors in Merleau-Ponty's passage: the notion of habit, the centrality of the text, and the idea of rhetorical gesture. Ultimately, I conclude that in the embodied event of an 
organ performance, the instrument itself becomes the medium, the faculty, and the possibility of authentic communication between musician and audience.

\section{Making Oneself at Home}

From a first reading of Merleau-Ponty's sketch, it is evident that the habits at issue are those which transform the organist's abilities from the mechanical repetition of keyboard and pedal techniques into the free faculty of acquainting oneself with a new instrument in a matter of minutes (Casey, 1984; Fuchs, 2012; Paparo, 2016). Jakub Čapek (2017) utilizes the phrase "the genealogy of habit" (p. 435) to capture this process of transformative learning. I am not convinced, however, that this is the main thrust of Merleau-Ponty's point in the particular passage under consideration. Habit is itself a far richer metaphor for our faculties of being-in-the-world; habit is more than mere routine. And if Merleau-Ponty is the "philosopher of habit" par excellence (Semon, 2009, p. 105), the implications of one's habits - musical, rhetorical, and otherwise —offer keys to his philosophy as a whole.

As classical scholars have demonstrated, the Greek word êthos includes a wide spectrum of meanings, including "habit," "habituation," and "character" (Baumlin, 2001; Chamberlain, 1984; Halloran, 1982; Reynolds, 1993). Habits are the places that we live as much as the ways that we live: "To live somewhere, to live in some place, is to have it through one's habits" (Semon, 2009 , p. 102). A person's èthos, far from a rigidified and immovable set of characteristics, shifts and develops over time. This seems closer to the kind of habits Merleau-Ponty (1944/2012) is describing, especially in his metaphor of "sedimentation": the gradual development of a corpus of implicit understanding which forms the background for human action (pp. 131-132). Our memory of experiences in the world disposes us to develop certain habits: certain ways of being at home in the world (Casey, 1984, pp. 284-285). Our ways of carrying ourselves allow us, in language Merleau-Ponty applies to the organ example, to settle into the world as one settles into a house. Hence the centrality of èthos to Aristotelian rhetoric; it is precisely this bearing during a speech, this comportment, which furnishes the rhetor with credibility and wins favor from the audience (Sullivan, 1993). Again, however, habituation remains flexible. It represents skilled mediation that navigates between the virtual and the real, between the universal and the particular. "Habit is thus in a middle range position, situated between the very extremes of custom and spontaneity which it nonetheless serves to mediate" (Casey, 1984, p. 287). The organist's ability to interpret a new field of possibilities at an unfamiliar bench exemplifies his or her sedimented capacity to apply the general features of organ playing to a particular situation.

But habit, as a means of making oneself at home, is more than a metaphor. Habit returns us to the embodied context of all human experience. If habit is temporally acquired, it is also spatially oriented, consisting in "an intuitive incorporation of the space in which it is enacted" (Casey, 1984, p. 286). When confronted with an unfamiliar space, a person's instinct is to look around, to size it up, to explore its nooks and crannies in the hopes of making oneself at home in it. The situatedness of the lived world is indispensable. Thus, the organ example speaks to MerleauPonty's critique of empiricism more generally (Viljoen, 2010). At a certain point, abstract definitions of the pipe organ cease to provide the performer with useful knowledge. There is no 
such thing as a theoretical pipe organ on a vacant stage, illuminated with a single spotlight. ${ }^{2}$ The very essence of the pipe organ is its situatedness within a particular building and context: not objective space, but actual lived space. Every organ possesses a unique combination of pipes, a distinct timbre, a particular console layout, and a singular set of mechanical quirks and flaws, not to mention the vast variety of sonic possibilities enabled or excluded by the building in which it is set. And the primary entrance afforded to the organist for knowledge in this space is through tactile engagement with the instrument itself. The "experience of built space" (Viljoen, 2010, p. 306) in an organ performance is one in which the very building becomes an instrument of musical expression.

The above observations on the nature of organ acoustics become significant in considering the inherent meaningfulness of space in the phenomenological tradition. To ascribe a "fundamentally spatial character" to meaningfulness emphasizes that our process of understanding the world is itself embodied (Marratto, 2012, p. 39). In the rehearsal, the organist's task is clear: to make sense of the myriad stops, tabs, knobs, and pedals presented at an unfamiliar console, and to translate this data into situational knowledge that will enable him or her to produce a work of art. The presence of meaning is presupposed in such an encounter: the organist proceeds from the assumption that the layout and tonal design of the instrument reflect purposefulness and intentionality on the part of its builder. This purposefulness comes to meet the organist through the physical "affordances" of the console (Marratto, 2012, p. 43) - the musical possibilities that the particular arrangement of stops and keyboards opens or closes. ${ }^{3}$ Under the hands of the experienced organist, these mechanical features become "opportunities for action" (Berendzen, 2014, p. 169). Through rehearsal and performance in the lived space of the organ, the organist recovers, expands upon, and moves beyond the meaning that the instrument's creator built into it.

But the organist's desire extends beyond the goal of feeling at home on the bench. Ultimately, the organist wishes to explore the space itself, and the organ presents itself as an instrument by which that intention can be accomplished. Consider Merleau-Ponty's most famous illustration of technological affordances: the blind person's cane (Merleau-Ponty, 1944/2012, pp. 153-154; see DeSouza, 2017, pp. 20-21). Through habituation, a cane ceases to be a part of the user's world and becomes an extension of the body itself. No longer a "perceived object," the cane for the blind "becomes that through which they perceive" (Maclaren, 2006, p. 147, emphasis original). Sensation radiates outward to the tip of the cane to provide the blind person with "motor imagery" that the faculty of sight could never provide (Berendzen, 2014, p. 169). Extended to the whole of human experience, such an example emphasizes that "the body is a primary mode of knowing" (Juntunen \& Hyvönen, 2004, p. 2). Our tactile and sensory interactions with tools inform our understanding of the spaces we live in via what Juhani Pallasmaa (2009) calls "the thinking hand" (see also Moores, 2014). Knowledge is discovered, then, in skilled interaction between the organ of perception and lived space, mediated by the materiality of the instrument at hand.

\footnotetext{
${ }^{2}$ For this reason, creating a sample set for a digital organ requires careful attention to reproducing the unique imperfections of each pipe and the reverberation of the space (Milan Digital Audio, 2020). Yet even the most successful digital organ technology leaves something to be desired when compared to a real acoustic instrument.

${ }^{3}$ The notion of affordances - possibilities for action which present themselves to the self in the physical environment — derives from the work of American psychologist J. J. Gibson (1966; 1979). However, a similar idea is implicit throughout Merleau-Ponty's phenomenology.
} 
Although it would be the focus of an entirely different study, the distinguished line of blind organists who flourished in France in the nineteenth and twentieth centuries is worth mentioning here. Ann Labounsky (2000) has documented the life of Jean Langlais (1907-1991) as an exemplar, particularly through his involvement in the National Institute for the Blind. The virtuosity of Langlais and his associates exemplifies the phenomenological reality that "to acquire a new habit. . .is. . to acquire a new way of perceiving" (Maclaren, 2006, p. 147). Blind organists cultivate extraordinary, almost superhuman, faculties of memory and tactile/aural attentiveness in order to learn the relative positions of the various keyboards, the location of the stops, the distance of the pedals from the bench, and so on. If the pipe organ takes a building and transforms it into an instrument, the organist takes the instrument and transforms it into an extension of the body. The organ is not a mere point of reference within the space; it becomes my very means of knowing the space. Through it I measure the height of the arches and the width of the transept. Through it I sense the distance from one end of the church to the other by judging the time it takes for the reverberations to reach my ear. Through it I feel the cushions on the pews or the hardness of the slate floor, and I explore the nooks and crannies to which my own body could never gain access. It is not the space that allows me to size up the organ; it is the organ that enables me to size up the space (Maclaren, 2006, p. 147).

In short, the pipe organ functions as an extension of the faculties of bodily sensation, engaging the senses of sight, sound, touch, and even smell in such a way that a heightened awareness greater than the sum of its parts emerges. Quite literally, the instrument becomes an organ - a sense organ that informs my understanding of the space around me and its capacities for expressive action. The forms of our tools shape our deepest understanding of reality and work, as articulated in Matthew Crawford's afterword on the organ builder's shop in The World Beyond Your Head (2015). To put it a slightly different way, what the pipe organ demonstrates is that the embodied situatedness of human life is where we encounter meaning itself - an observation which problematizes positivism and radical social constructionism alike (Juntunen \& Hyvönen, 2004, p. 11). Meaning neither sits stagnant in the world, like a jack-in-the-box waiting to be unwound, nor hovers above it in an ever-shifting ether of ideas. Rather, meaning emerges along the hairline border of our bodily experience with the material world. The body makes meaning, Merleau-Ponty (1944/2012) says, in that "it projects significations on the outside by giving them a place and sees to it that they begin to exist as things, beneath our hands and before our eyes" (p. 147). Meaning springs forth simply as a gift from this human encounter with the world; it is not so much that we understand, but rather that understanding comes and meets us there, in the pew or at the organ bench.

\section{Being Confronted by the Text}

So far we have seen that the power of habituation enables the organist to create an expressive space in which the medium of the instrument withdraws into the musical event taking place. But there is a further hermeneutical problem inherent in Merleau-Ponty's critique of abstraction: What is the role of the musical score in this engagement of meaning? Although it is not uncommon for an organist to improvise, more often he or she performs by reading and interpreting a score: a set of symbolic abstractions which, as such, are anything but expressive. Even a memorized performance first requires hours of study within the confinements imposed by a written score. Musical educators are no strangers to the challenges this mummified "text" containing coded directives for pitch, rhythm, and expression poses when students are "taught 
theory by rules and writing, not by sound" (Juntunen \& Hyvönen, 2004, p. 1). And digital metaphors for music production only exacerbate the tension between the abstract and the concrete which characterizes musical skill (Kujundzic \& Buschert, 1994; Lindell \& Kumlin, 2017). For these reasons, the technology of the written score would seem to bind and hamper the organist's expressive abilities. But Merleau-Ponty does not see it this way; in fact, his treatment of the organ affirms a central role that the text plays in bringing meaning to light during the performance.

If the organ is a medium of understanding space, the score becomes a medium of understanding time. Jonathan de Souza (2017) examines this phenomenological observation in his work Music at Hand: Instruments, Bodies, and Cognition. De Souza describes how, as the elements of a score "coalesce into melodies and chords," the score becomes "less an object of perception than a medium for perception" (p. 21). The result of a skilled rendering of a musical text (called, not without reason, an "interpretation") is what de Souza calls "music that sounds like it feels good to play" (p. 81). The auditory experience reflects the phenomenological distinction between what Merleau-Ponty (1944/2012) refers to as "natural time" and "historical time" (pp. 361-362), which perhaps parallels the difference between objective and expressive space. The situatedness of the organ opens a space in which a temporal interpretation of a written score can occur. And the materiality of the score, like the materiality of the pipe organ, becomes an invitation for the experience of temporal understanding.

Note, however, that the "text" of the musical performance also has a referent above and beyond the actual materiality of the score which the organist uses to learn the performance. In their training, blind organists must learn the same compositions of organ literature without the aid of a traditional musical score, and Braille adaptations of music notation present a unique set of challenges (Labounsky, 2000). Thus, the artifact which the organist seeks to understand is not the score itself, but the piece of music which is communicated through it. Likewise, the audience, who have no access to the written score, must seek to make sense aurally of the performance that is delivered in their presence. The score, like the instrument, withdraws into the fabric of perception that Merleau-Ponty (1944/2012) describes in terms of "the music exist[ing] for itself" (p. 147). Score and instrument mark a spatial and temporal opportunity for understanding.

Think of the musical dynamics at issue: The novice organist first begins to render a piece with a wooden interpretation that conforms exactly to the natural time of the metronome. Not even a march is beautiful in strict metronomic time. As the student matures, he or she learns to translate the signs on the page into expressive invitations into historical time. The stretching of beats not only facilitates the pauses for breath mentioned earlier, it also directs the performer's and listeners' foci of attention, highlighting a momentary dissonance, a melodic peak, or a rhythmic surprise. This is the art of the agogic accent, and it defies symbolization on a piece of paper (Thiemel, 2001). Those who can play this way and those who can hear this way experience time in an entirely different way during the music. Natural time vanishes into historical time in an experience that allows the listener to encounter temporal understanding and to leave the performance a permanently changed person. Merleau-Ponty (1944/2012) writes: "I am never at one with myself. Such is the fate of a being who is born, that is a being who once and for all was given to himself as something to be understood" (p. 362). Music is thus a hermeneutic invitation for this sort of self-understanding.

Historical time underscores the significance of Merleau-Ponty's (1944/2012) description of the organist "entirely giving himself over to the music" (p. 147). It calls to mind Hans-Georg Gadamer's treatment of historically effected consciousness in Truth and Method (1960/2004), including the profound reversal that occurs when the musician, like the reader, is "pulled up short 
by the text" (p. 280). Although at first it seems that I understand the music through the medium of the score, it is rather the music through the medium of the score which comes to understand me. Truly in that moment "the music exists for itself and everything else exists through it" (MerleauPonty, 1944/2012, p. 147). There are ethical overtones here: the music makes certain demands upon me, which, once I am attuned to them, cannot be ignored. Kym Maclaren (2006) offers a phenomenological description of virtue ethics as "being moved bodily by an imperative we perceive within our particular situation" (p. 147). The subterranean rumble of a thirty-two-footlong Open Diapason pipe or the scream of a four-foot Clarion make certain bodily demands upon any listener. Many a proverbial person on the street has found his or her footsteps leading into a church in response to a "call" that the strains of music announced on the sidewalk. Little wonder that music is involved not only in worship, but in calls to worship as well. The musical text, as brought to life in the performance, issues a call.

The piece of music, the text, provides a form within which expressive space can be born and flourish. Even improvisations begin with readily available material: a familiar melody or a simple harmonic progression. There is no such thing as musical improvising out of whole cloth, any more than the possibility of disembodied Cartesian thinking-in-the-void. Whether in improvisation or in rendering an existing composition, musical expression requires physical form in order to appear. Yet the existence of a text is not itself beautiful until taken up and embodied by a human agent for a particular setting and time.

What occurs in such an interaction between person and text defies vocabulary, but a word we might fall back upon is "consecration"- and this is precisely the term that Merleau-Ponty uses. Through the organist, the ordinary space and time of a recital or a service becomes sacred space and time. We often connect the sacred to religion, to universality, to metaphysics, to abstraction. But there is another dimension to sacredness. Sacralization is the setting apart of particular places and times - a moment of transcendence which is striking only because it occurs in the midst of a very ordinary field of action. Martin Buber's description of the hallowing of the everyday (1960, p. 88) emphasizes the incarnational aspect of the sacred. The organist is not the sole agent for the creation of the sacred in the midst of a recital. But he or she may very well be the site at which a moment of transcendence springs forth in the apparently ordinary interaction of musician, instrument, audience, and space.

\section{Postlude: The Organ Recital as Rhetorical Gesture}

These phenomenological observations about the nature of the pipe organ form just the beginning stages of inquiry into the implications of musical performance as an embodied event. But it is impossible to leave off here without dealing, albeit briefly, with the relationship of this study to Merleau-Ponty's notion of intersubjectivity. The phenomenological situation of the pipe organ is incomplete unless it takes into account the relationship that the instrument brings into being between the performer and the audience. Building on the scholarship of phenomenologists who have traced the centrality of language in Merleau-Ponty's work, I suggest in this final section that understanding a pipe organ performance as rhetorical gesture unites the themes of habit and consecration involved in this intriguing passage.

The broader climax of Phenomenology of Perception is the radically non-objective phenomenon of intersubjectivity - and the carrier of this intersubjectivity is language. Significantly, Alphonso Lingis (1979) describes a phenomenological view of language as an "organon" (p. 57). In other words, language becomes not merely transport for my fully conceived 
thoughts, but the very instrument through which I think together with others. Merleau-Ponty (1944/2012) approaches speech as "something of a miraculous extension of [the body's] own intentions" in the body of another: "In the experience of dialogue . . . [w]e are, for each other, collaborators in perfect reciprocity: our perspectives slip into each other, we coexist through a single world" (p. 370). The miracle of communication is that for a moment, the bodies of speaker and listener are bound together in the fleeting phenomenon of language.

The importance of the embodied speech situation is a focal point of twentieth-century rhetorical scholarship (Arnold, 1968; Bitzer, 1968; Halloran, 1982). The connection between rhetorical and phenomenological notions of situatedness is captured by Dale L. Sullivan's (1993) work relating the embodiment of the rhetorical situation back to the classical notion of ethos. Sullivan describes this dwelling place as "the consubstantial space which enfolds participants" (p. 114). Consubstantiality occurs as a rhetor transcends time, inviting his or her audience to participate in "a common mental or spiritual space" (p. 127). Sullivan goes so far as to call this rhetorical space "sacred" (p. 128), and his description proves consistent with Merleau-Ponty's idea of consecration in the pipe organ passage. Rhetoric is a sacralizing activity: it sets apart an otherwise ordinary place and time for the extraordinary phenomenon of human speech and deliberation to take place (Mickunas, 2006, p. 148). In articulations of the rhetorical situation such as Bitzer's (1968), it is the situation itself which offers a call to speech, which is then heeded by the rhetor who realizes his or her ethical responsibility.

Into this embodied speech situation the rhetor offers a gesture which stirs up the affections of the audience. This gestural conception of rhetoric is a key implication of Merleau-Ponty's idea of intersubjectivity (Acheson, 2008; Fisher \& Lochhead, 2002; Mickunas, 2006). The empirical and phenomenological space affords opportunities for rhetors to engage in physical, verbal, and phenomenological motion, which, in turn, moves their audience. Ralph Bathurst and Trudie Cain (2013) build from Merleau-Ponty's organ example to argue that just as "musical instruments ... [offer] performers gestural tools ... that enable them to incorporate audiences into expressive moments," so too "leadership behaviours . . . also rely on gestures that occur in time and space" (p. 359). Just as skill at the organ bench involves the ability to "settle into the organ," skilled leadership involves the acquired habit of "settling into' an embodied relational dynamic" (p. 363). Bathurst and Cain conclude that "leadership is an incarnate activity that occurs in the moment as people invite others into spatially-bound and temporal relationships" (p. 372). The organ thus serves as an analogue for the responsive and attentive embodied wisdom of the orator, who adapts his or her discourse to fit the needs of a given rhetorical situation.

But is it possible to relate the linguistic experience of intersubjectivity more directly to the realm of music? Without becoming embroiled in the larger question whether music is a form of language or only an analogue of it, here I would merely suggest one important similarity: music, like language, offers an embodied experience of shared meaning that binds participants together. ${ }^{4}$ George Fisher and Judy Lochhead (2002) interpret Merleau-Ponty's notions of intersubjectivity and intercorporeity to suggest "an understanding of musical meaning that resides not simply in the constituting agency of the composer but in the shared and bodily-based activities of creator, performer, and listener" (p. 39). A similar perspective is articulated in Colwyn Trevarthen's (1999)

\footnotetext{
${ }^{4}$ Consider the remarkable popularity of livestreamed pipe organ concerts during the worldwide isolation measures imposed during this year's coronavirus pandemic (Kearney, 2020). Viewers frequently comment that listening to such concerts offers the chance to make sense out of a confusing and depressing time. Paradoxically, however, the success of these concerts also points to audiences' longing for the irreplaceable experience of a flesh-and-blood musical event.
} 
concept of the "intrinsic motive pulse," which seeks to discern the bodily origins of musical understanding common to humanity. This meaning communicated through the music "organ-izes" (Küpers, 2012, p. 114): it creates a particular moment in which performer and audience can unite around a common centre. The physical artifacts of instrument and score become media through which this moment of shared meaning emerges.

If this is so, the "expressive space" that the organist creates is an ethical and aesthetic response to the affordances of the instrument, the space, and the musical work to be interpreted. More than that, it is a venture into communion with the audience that gathers in the space. Under the hands of the skilled organist, the pipe organ becomes not merely an instrument for understanding the space, but an instrument for understanding the audience - and an instrument whereby the audience can gain a fleeting glimpse of the underlying character (the éthos) of the performer. The nature of such a performance is intensely dialogic, even when the voice of the organ is the only sound empirically present. The organ is the skilled organist's means of listening to the audience. Through it the organist weighs and interprets the meaning of the audience's silence and attempts to speak into it with a musical word that will seep into their souls (Acheson, 2008). And in leading congregational singing, which is perhaps what it does best, the organ aims to provide support that ultimately vanishes into the fabric of corporate song, lifted up by the human chests and lips of which its wood and metal contrivances are only an imperfect approximation. In song, the organist responds to the inflections of the assembly and they respond to the organist's, as both attend to the ethical demands made upon them by the text and the music (Cimini, 2012, p. 362). In this sense, the organist's musical leadership is ambiguous; it represents "the possibility of speaking imaginatively, poetically; yet with integrity" (Eicher-Catt, 2005, p. 126). It is this dialogic experience that consecrates the organ recital as a rhetorical gesture.

\section{Conclusion}

This investigation into Merleau-Ponty's description of the pipe organ contributes to a richer understanding of the phenomenology of practice. Practices involve not only a specific set of actions but also the habits that comprise an individual's character or ethos. And practice, in the singular, is embodied engagement with the materiality of an instrument which prepares for the performative possibility of this character to become apparent. The habitual practices that constitute virtuosity at the organ prepare the performer for hermeneutic engagement with the texts of instrument and score and provide the possibility for temporal meaning to emerge. Skilled interpretation at the organ bench sacralizes ordinary space and time for the intersubjective experience of communication. The organist works in the role of rhetor, offering ethical and aesthetic gestures that invite the audience into a moment of understanding, reflection, and transformation. And this observation speaks to the domain of human communication more generally. The gestures of the rhetor, like the gestures of the organist, are "gestures of consecration" (Merleau-Ponty, 1944/2012, p. 147), and they offer those who wander past the doors of a communicative dwelling place the opportunity to pause for a moment and even, perhaps, to come in. 


\section{References}

Acheson, K. (2008). Silence as gesture: Rethinking the nature of communicative silences. Communication Theory, 18(4), 535-555.

Arnold, C. C. (1968). Oral rhetoric, rhetoric, and literature. Philosophy and Rhetoric, 1, 191210.

Associated Pipe Organ Builders of America. (2018). Planning space for pipe organs. http://apoba.com/resources/publications/planning-space

Augustine of Hippo. (1966). Enarrationes in psalmos LI-C. D. E. Dekkers \& I. Fraipont (Eds.). Brepols.

Augustine of Hippo. (2001). Expositions of the psalms 51-72 (M. Boulding, Trans.). J. E. Rotelle (Ed.). New City Press.

Bathurst, R., \& Cain, T. (2013). Embodied leadership: The aesthetics of gesture. Leadership, 9 (3), 358-377.

Baumlin, J. S. (2001). Ēthos. In T. O. Sloane (Ed.), Encyclopedia of rhetoric (pp. 263-77). Oxford University Press.

Berendzen, J. C. (2010). Coping without foundations: On Dreyfus's use of Merleau-Ponty. International Journal of Philosophical Studies, 18(5), 629-649.

Berendzen, J. C. (2014). Motor imagery and Merleau-Pontyian accounts of skilled action. Ergo: An Open Access Journal of Philosophy, 1(7), 169-198.

Bitzer, L. F. (1968). The rhetorical situation. Philosophy and Rhetoric, 1, 1-14.

Buber, M. (1960). The origin and meaning of Hasidism. New York, NY: Horizon Press.

Čapek, J. (2017). Habit and freedom in Merleau-Ponty and Ricoeur. Journal of Speculative Philosophy, 31(3), 432-443.

Casey, E. S. (1984). Habitual body and memory in Merleau-Ponty. Man and World, 17, 279-297.

Chamberlain, C. (1984). From haunts to character: The meaning of èthos and its relation to ethics. Helios, 11(2), 97-108.

Cimini, A. (2012). Vibrating colors and silent bodies: Music, sound and silence in Maurice Merleau-Ponty's critique of dualism. Contemporary Music Review, 31(5-6), 353-370.

Crawford, M. B. (2015). The world beyond your head: On becoming an individual in an age of distraction. Farrar, Straus and Giroux.

Davis, R. E. (1985). The organists' manual: Technical studies and selected compositions for the organ. W. W. Norton \& Co. 
De Souza, J. (2017). Music at hand: Instruments, bodies, and cognition. Oxford University Press.

Eicher-Catt, D. (2005). The authenticity in ambiguity: Appreciating Maurice Merleau-Ponty's abductive logic as communicative praxis. Atlantic Journal of Communication, 13(2), 113134.

Fisher, G., \& Lochhead, J. (2002). Analyzing from the body. Theory and Practice, 27, 37-67.

Fuchs, T. (2012). The phenomenology of body memory. In S. C. Koch, T. Fuchs, M. Summa, \& C. Müller (Eds.), Body memory, metaphor and movement (pp. 9-22). John Benjamins Publishing Company.

Gadamer, H.-G. (2004). Truth and method (2nd ed., J. Weinsheimer \& D. G. Marshall, Trans.). Bloomsbury. (Original work published 1960)

Gibson, J. J. (1966). The senses considered as perceptual systems. Houghton-Mifflin Co.

Gibson, J. J. (1979). The ecological approach to visual perception. Houghton-Mifflin Co.

Guinness World Records. (2020). Largest organ. https:/www.guinnessworldrecords.com/worldrecords/69723-largest-organ

Halloran, S. M. (1982). Aristotle's concept of ethos, or if not his somebody else's. Rhetoric Review, 1(1), 58-63.

Juntunen, M.-L., \& Hyvönen, L. (2004). Embodiment in musical knowing: How body movement facilitates learning within Dalcroze Eurhythmics. British Journal of Music Education, 21(2), 1-16.

Kearney, M. R. (2020). Many gifts, one spirit: Dutch organ virtuoso Gert van Hoef uses his talent to serve the global church [Interview with G. van Hoef.]. Christian Renewal, 38(11), 2428.

Kujundzic, N., \& Buschert, W. (1994). Instruments and the body: Sartre and Merleau-Ponty. Research in Phenomenology, 24(1), 206-215.

Küpers, W. M. (2012). "Inter-communicating:" Phenomenological perspectives on embodied communication and contextuality. Journal for Communication and Culture, 2(2), 114-138.

Kuyper, A. (2009). Our worship (H. Boonstra, H. Baron, G. Sheeres, \& L. Sweetman, Trans.). H. Boonstra (Ed.). Wm. B. Eerdmans Publishing Co. (Original work published 1911)

Labounsky, A. (2000). Jean Langlais: The man and his music. Amadeus Press.

Lindell, R., \& Kumlin, T. (2017). Augmented embodied performance: Extended artistic room, enacted teacher, and humanisation of technology. New Interfaces for Musical Expression, 2017 conference proceedings, 77-82. 
Lingis, A. (1979). The difficulties of a phenomenological investigation of language. Modern Schoolman, 57(1), 56-64.

Maclaren, K. (2006). Merleau-Ponty's embodied ethics: Rethinking traditional ethics. In C. Daigle (Ed.), Existential thinkers and ethics (pp. 142-166). McGill-Queen's University Press.

Marratto, S. L. (2012). The intercorporeal self: Merleau-Ponty on subjectivity. Albany, NY: State University of New York Press.

Merleau-Ponty, M. (2012). Phenomenology of perception (D. A. Landes, Trans.). Routledge. (Original work published 1944)

Milan Digital Audio. (2019). Hauptwerk features. https://www.hauptwerk.com/features/

Owen, B., Williams, P., \& Bicknell, S. (2001). Organ. Grove Music Online. https://doi.org/10.1093/gmo/9781561592630.article.44010

Oxford English Dictionary. (2019). Organ, n. 1. Oxford, UK: Oxford University Press. http://www.oed.com/view/Entry/132421

Pallasmaa, J. (2009). The thinking hand: Existential and embodied wisdom in architecture. John Wiley \& Sons.

Paparo, S. A. (2016). Embodying singing in the choral classroom: A somatic approach to thinking and learning. International Journal of Music Education, 34(4), 488-498.

Provincial Synod of Dordrecht (1982). Church order selected from the acts of the provincial synod of Dordrecht held on 15 June 1574. In P. Biesterveld \& H. H. Kuyper (Eds.), Ecclesiastical manual, including the decisions of the Netherlands synods and other significant matters relating to the government of the churches (R. A. de Ridder, Trans., pp. 59-80). Grand Rapids, MI: Calvin Theological Seminary.

Reynolds, N. (1993). Ethos as location: New sites for understanding discursive authority. Rhetoric Review, 11(2), 325-338.

Semon, K. (2009). The habit of inhabitation: Rethinking digital design via Merleau-Ponty and Proust. Environment, Space, Place, 1(1), 101-119.

Sullivan, D. L. (1993). The ethos of epideictic encounter. Philosophy \& Rhetoric, 26(2), 113-133.

Thiemel, M. (2001). Agogic. Grove Music Online. https://doi.org/10.1093/gmo/9781561592630.article.00296

Trevarthen, C. (1999). Musicality and the intrinsic motive pulse: Evidence from human psychobiology and infant communication. Musicae Scientiae Special Issue 1999-2000, $155-215$. 
Viljoen, M. (2010). Embodiment and the experience of built space: The contributions of MerleauPonty and Don Ihde. South African Journal of Philosophy, 29, 306-329.

Williams, C., \& Walker, J. (2018, July 6). John Walker “on the bench with Dr. Carol” [Video]. YouTube. https://youtu.be/KrcK1qLY2eA 